\title{
A Simulation Approach to Evaluate Operational Economics of Wind Power Investments in Turkey
}

\author{
Ahmet Yucekaya
}

\begin{abstract}
It is crucial to analyze the wind distribution throughout the year and the expected annual power generation (Mwh) to evaluate a wind power investment. The cut-in and cut-out wind speeds along with the size of the wind turbine should carefully be included to the analysis as they will affect the amount of power generation. On the other hand, the capital cost and cost of power generation each year should be allocated to the economic life of the project using an appropriated discount rate. In this paper, an economic analysis method and a wind simulation approach is developed to evaluate the expected annual power generation of a wind project. The revenue is calculated using expected power amount and the power price (\$/Mwh) and the net return is found by subtracting the cost. The necessary economic analysis is then performed using net present value and payback method. The weibull distribution is assumed for the wind and operational characteristics of the turbine are included.
\end{abstract}

Index Terms-Wind power, economic analysis, wind simulation, turbine operational constraints.

\section{INTRODUCTION}

After the 90's the importance of wind power has grown tremendously as the demand for energy and the cost of fossil fuels increased. Especially after the price fluctuiations in coal and natural gas in recent years has led the wind power investments more attractive and economic. The cost distributions in fossil fuel based power plants and wind power are different, the wind power investmens require a huge initial capital cost and there is no fuel cost. On the other hand, 55\% of total cost in fossil based plants is accepted as the fuel cost [1]. This difference should be carefully considered and the analysis should be performed before the actual investment is made. The wind distribution of a particular site, the characteristics of the wind over the years ahead would certainly affect the amount of power produced. However, not many analysis are available to help energy companies when they analyze the long term behaviour of the wind turbine and its economic analysis. The main objective of such studies is to decrease the uncertainity and prevent the huge losses if the investment is already made and not much revenue is gained to cover the expenses in the future.

All wind turbines installed globally by the end of the year 2009 provides $2 \%$ of the global electricity demand and this is growing with an average of $25 \%$ annuam [2]. The growth rate especially for developed countries is double digit and it is expected that renewable resources would provide $20 \%$ of

Manuscript received July 5, 2014; revised August 29, 2014.

Ahmet Yucekaya is with the Kadir Has University, Fatih, İstanbul, Turkey (e-mail: ahmety@khas.edu.tr). total energy demand in the near future. There are also incentives from the goverments to led wind farms grow. Such concerns also trigger the investments for wind farms. However the economic analysis especially in the energy industry is vital as competition is fierce and there is little chance that an uneconomic project will survive.

Wind turbines come in different sizes and configurations and are built from wide range of materials. Simply, a wind turbine consists of a rotor that has wing shaped blades attached to a hub; a nacelle that houses a drive train consisting of a gearbox, connecting shafts, support bearings, the generator, plus other machinery; a tower; and ground mounted electrical equipment. The major cost components in the initial capital cost are usually classified as hardware cost, logistic cost, consumable costs, and land cost [3]. The revenues on the other hand are the sale revenue gained from the sale of generated power to the system operator. The technical lifetime is usually accepted as 20 years without renewing, however this might change as the cost changes. There are many uncertanities associated with the invesment decision and each uncertanity should carefully be included to the model for a better decision [4]-[6].

Under these conditions, a model that includes the turbine operation constraints and economic analysis is needed. In this paper, a model for wind turbine is developed and integrated with the economic analysis over the years. Section II gives overview of the model formulation and assumptions. Section III gives numerical results gained from the application. The conclusion is given in Section IV.

\section{OPERATION OF THE WIND TURBINE}

\section{A. Model Formulation}

The energy extracted from a wind turbine is linearly related to the area and polynomial to the wind speed. The size of the blades and height of the tower which will determine the size of the investment will affect the power output. A wind turbine obtains its power input by converting the force of the wind into torque acting on the rotor blades. The amount of energy which the wind transfers to the rotor depends on the density of the air, the rotor area, and the wind speed. The formulae for the power in a wind turbine is given as

$$
\text { Hub Power }=\frac{1}{2} \rho A V^{3} C_{p}
$$

where $A$ is the area, $\rho$ is the air density, $V$ is the wind speed and $C_{p}$ represents the coefficient of power. Area is also called the 'capture area' which is the location swept by the blades is the circler which is calculated as pix Radius ${ }^{2}$ as given below, 


$$
A=\frac{\pi R^{2}}{4}
$$

The kinetic energy of a moving body is proportional to its mass (or weight). Therefore, the kinetic energy in the wind depends on the density of the air. In other words, when the air is heavier, the more energy would be received by the turbine. At normal atmospheric pressure and at $15^{\circ}$ Celsius air weights some $1.225 \mathrm{~kg} / \mathrm{m}^{3}$ but the density decreases slightly with increasing humidity. At high altitudes, (in mountains) the air pressure is lower, and the air is less dense. The air density [3], [7], is represented as

$$
\rho=\frac{101300 \times\left[1-\frac{0.0065 \times \text { altitude }}{288}\right]^{\frac{9.806655}{0.0065 \times 287.15}}}{287.15 \times(288-0.0065 \times \text { altitude })}
$$

Average wind speeds are often available from meteorological observations measured at different levels. However, the wind speed at the hub height is needed to be used in the analysis. Using a shear exponent the wind speed at a particular height [3] can be found

$$
\bar{V}=\left(\frac{H u b H e i g h t}{H_{0}}\right)^{\text {shear }} V_{0}
$$

Coefficient of power, $C_{p}$, is how efficient the wind turbine converts energy in the wind into electricity. This coefficient includes the Betz limit and the wind turbine efficiency [3], [7].

The behavior of the wind at a particular site changes very often and follows a time series. It also means that the energy amount which is harvested from the wind may change over the time. Instead, the weibull distribution is accepted as the way to explain the wind behaviors in the literature. We found the weibull parameters from the given wind data and used to compute weibull probabilities for given wind intervals. The weibull distribution can be represented as,

$$
\operatorname{Weibull}(V, K, c)
$$

The statistical parameters for the given wind data such as average and variance are needed to be calculate the weibull parameters [6].

$$
\bar{V}=\frac{1}{n_{i}} \sum_{i=1}^{n} V_{i} \quad \sigma^{2}=\frac{1}{n-1} \sum_{i=0}^{n}\left(V_{i}-\bar{V}\right)^{2}
$$

Then $c$ and $K$ can be calculated using these statistics.

$$
c=\frac{\bar{V}}{\Gamma\left(1+\frac{1}{k}\right)} \quad K=\left(\frac{\sigma}{\bar{V}}\right)^{-1.086}
$$

In order to operate a particular wind turbine, a minimal wind is required called cut-in wind speed. At this step the turbine will operate but will not perform at its full capacity.
The turbine will reach its expected capacity at the speed called rated wind speed. The turbine will operate at this capacity until the point at which the wind speed is high enough to become a danger for the turbine. The turbine will stop at this wind speed called cut-out wind speed. The hub power gained from the turbine can be represented as in the Table I.

TABLE I: WIND SPEEDS AND HuB POWER

\begin{tabular}{|c|c|}
\hline Wind speed & Hub power \\
\hline$V<$ Cut-in wind speed & 0 \\
\hline Cut-in wind speed $<=V<$ Rated wind speed $\left(V_{r}\right)$ & $0.5 \rho A V^{3} C_{p}$ \\
\hline Rated wind speed $<=V<$ Cut-out wind speed & $0.5 \rho A r^{3} C_{p}$ \\
\hline Cut-out wind speed $<V$ & 0 \\
\hline
\end{tabular}

Then the turbine power would be

$$
P_{t}=P_{h} \eta
$$

$P_{t}$ is the turbine power and $\eta$ is the efficiency. The efficiency is found by comparing the generated power with the rated power and can be approximated as

$$
\eta=\frac{\frac{P}{P_{\text {rated }}}-\left(\text { Constant }+ \text { Linear } \times \frac{P}{P_{\text {rated }}}+\text { Quadratic } \times\left(\frac{P}{P_{\text {rated }}}\right)^{2}\right)}{\frac{P}{P_{\text {rated }}}}
$$

Constant, linear and quadratic are predetermined coefficients for the turbine. The turbine energy, $W_{t}$, is then would be the turbine power multiplied by the weibull probability $\left(W_{p}\right)$.

$$
W_{t}=P_{t} W_{p}
$$

The availability of the wind turbine, array losses and soiling losses should also be included to the model [3]. Including these parameters, the energy amount for one hour, $W_{h}$ can be calculated as in (11).

$$
W_{h}=\sum W_{t}(1-S L)(1-A L) U
$$

Here $S L$ represents soiling losses, $A L$ represents array losses and $U$ represents the availability. Availability is often times measured as the remaining percentage of time after the maintenance and outage times deducted from the whole year. Soiling losses and array losses might change depend on the age of the technology used. The annual energy would be multiplication of hourly expected energy with the number of hours in a year.

\section{B. Cost-Revenue Economics of Wind Farms}

A typical investment has an initial capital cost and net cash flows gained from the operation of the investment after deducting the cost. For a typical wind farm, the initial capital cost is huge comparing with the operation cost and fuel cost until the end of the project life. The economic feasibility of an investment is measured by its present worth and payback time. Present worth analysis is basically the current value of all the cash flows which will be gained in the future considering a 
appropriate interest rate. Given that revenue, $R_{t}$, initial capital cost, $C_{0}$, interest, $i$, and project life $n$, net present worth, NPW, can be formulated as follows:

$$
N P W=\sum_{t=1}^{n} \frac{R_{t}}{(1+i)^{t}}-C_{0}
$$

NPW will also give a chance to compare the investment with other oppurtunities. The payback period, which is the length of time that it takes to get your money back for a project, is another important parameter that is used in investment analysis. The payback time is also computed using the future revenues and initial capital cost.

\section{Simulation Approach}

It is not easy to predict or forecast the wind for a given time period due to its fluctuation in its nature. However, the past data of the wind would give a basis to make judgements about how much wind might blow over time. As the main objective of this research is to make an economic analysis of a wind turbine over time, one way to handle the uncertainity is to do a simulation on wind [8]. The expected wind then can be used to estimate the weibull parameters that will be used in the model. The model is implemented in a spreadsheet and integrated with the economic analysis tools as given in Fig. 1 below:

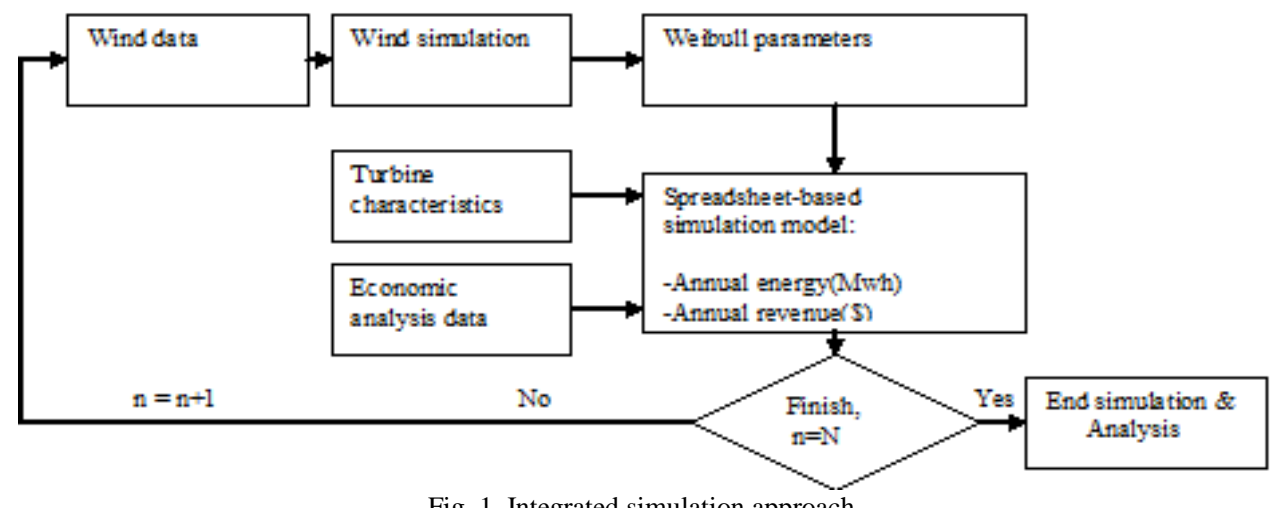

Fig. 1. Integrated simulation approach.

Using weibull distribution, the probability of occurrence is evaluated for the changes in the wind speed by a given interval from 0 to cut-out wind speed [3]. This probability would also give us how much energy might be generated from the wind turbine. These energy amounts then are summed and converted to the annual energy, which will give us revenue for this particular year.

\section{CASE STUDY}

The annual wind data for two different sites were collected from TUMAS for the analysis. The daily average wind speed at $1 \mathrm{mt}$ for Sanli urfa and Mersin is analyzed for 2007, 2008, and 2009 [9]. Fig. 2 and Fig. 3 below show the plot of the wind distribution over the year for Sanli Urfa and Mersin respectively.

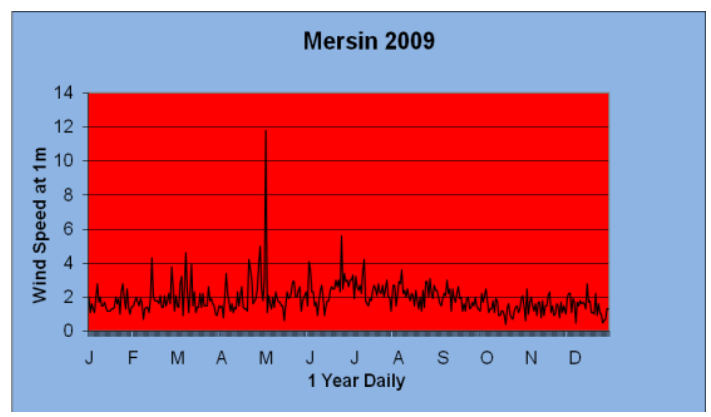

Fig. 2. Average daily wind speeds for Sanli urfa, 2009.

The wind for each time $t$ is accepted as a random variable which might fluctuate as $V t=V t \pm$ Rand. This wind speed then used to find the hub-level wind speed that will be used to generate power. The algorithm in spreadsheet-based simulation model evaluates the wind over the year and integrated economic analysis tools computes the revenue.
Table II shows the wind characteristics and weibull parameters for Sanli Urfa. The tribune data is provided from turbine producer companies Nordex and Vestas. Table III shows turbine characteristics for Nordex $1500 \mathrm{Kw}$ product. Table IV shows the turbine and wind parameters for $1500 \mathrm{Kw}$ turbine and Sanli urfa wind data.

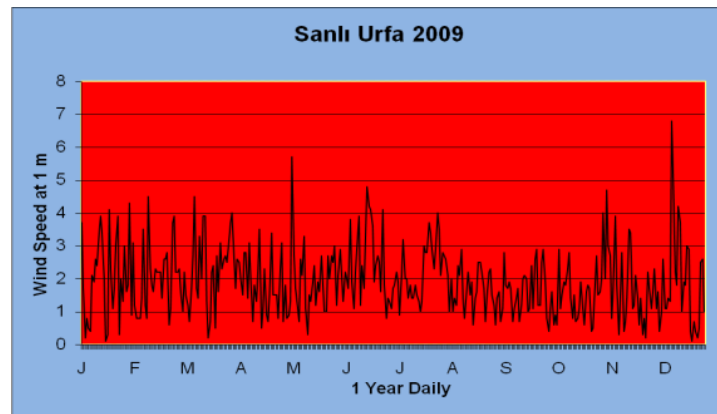

Fig. 3. Average daily wind speeds for Mersin, 2009.

TABLE II: WIND CHARACTERISTICS FOR SANLI URFA

\begin{tabular}{|r|r|}
\hline Wind Variance & 4.966344 \\
\hline Wind Standard deviation & 2.22853 \\
\hline Wind Average $(\mathrm{m} / \mathrm{s})$ & 3.965137 \\
\hline Weibull $k$ & 1.869651 \\
\hline Weibull $c$ & 3.965137 \\
\hline
\end{tabular}

TABLE III: TURBINE CHARACTERISTICS FOR $1500 \mathrm{KW}$

\begin{tabular}{|c|c|}
\hline Number of blades & 3 \\
\hline Rotor Diameter $(\mathrm{mt})$ & 78 \\
\hline Cut-in wind speed $(\mathrm{m} / \mathrm{s})$ & 3.5 \\
\hline Cut-out wind speed $(\mathrm{m} / \mathrm{s})$ & 25 \\
\hline Rated wind speed $(\mathrm{m} / \mathrm{s})$ & 13 \\
\hline Rated power $(\mathrm{kW})$ & 1500 \\
\hline Hub Height $(\mathrm{mt})$ & 81 \\
\hline Rotor Cp. & 0.35 \\
\hline
\end{tabular}


TABLE IV: TURBINE AND WIND SPECIFIC PARAMETERS FOR SANLI URFA

\begin{tabular}{|r|r|}
\hline Parameter & Value \\
\hline Rated power $(\mathrm{kw})$ & 1500 \\
\hline Rotor Diameter $(\mathrm{mt})$ & 78 \\
\hline Hub Height $(\mathrm{mt})$ & 81 \\
\hline Altitude $(\mathrm{mt})$ & 10 \\
\hline Rotor $\mathrm{Cp}$. & 0.35 \\
\hline Cut-in wind speed $(\mathrm{m} / \mathrm{s})$ & 3.5 \\
\hline Cut-out wind speed $(\mathrm{m} / \mathrm{s})$ & 25 \\
\hline Power law shear exponent & 0.143 \\
\hline Air density $(\mathrm{kg} / \mathrm{m} 3)$ & 1.225198 \\
\hline Hub Height wind speed $(\mathrm{m} / \mathrm{s})$ & 3.97648 \\
\hline Rated hub power $(\mathrm{kw})$ & 1530.612 \\
\hline Rated wind speed $(\mathrm{m} / \mathrm{s})$ & 11.39 \\
\hline Conversion Efficiency - constant & 0.02 \\
\hline Linear & 0.0155 \\
\hline Quadratic & 0 \\
\hline
\end{tabular}

The expected life of a wind turbine usually accepted as 20 years. The simulation will run for 20 years and the NPW and payback time will be based on 20 -years of simulation. The interest rate is accepted as $5 \%$. The capital cost of a wind turbine is approximated as $1000 \$ / \mathrm{kw}$ in the literature. The annual operating and maintenance cost is assumed to be $4 \%$ of the capital cost. The annual revenue is found multiplying the annual energy amount with $90.61 \$ / \mathrm{Mwh}$, which is the accepted price by the system operator in Turkey. A farm of 30 turbines is assumed and a simulation is performed. It is assumed that there is $3.5 \%$ soiling losses, $5 \%$ array losses and $98 \%$ availability over the year. Fig. 4 provides revenue and net income results and Fig. 5 provides information for the payback.

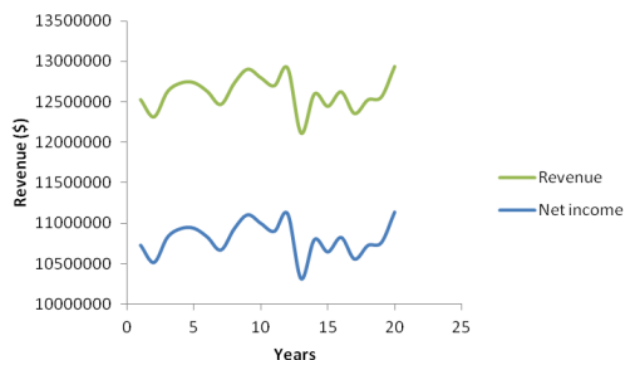

Fig. 4. Revenue and net income over the life of the project Sanlı Urfa.

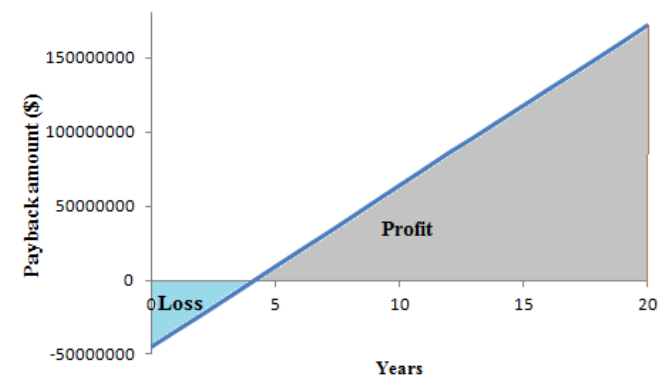

Fig. 5. Economic analysis and payback for the project Sanli ufra.

The results show that the NPW of the investment is $\$ 84,641,000$ and the payback time is 5 years for the Sanli Urfa project. The simulation for different sites and turbine combinations are also given in Table $\mathrm{V}$.

TABLE V: ECONOMIC ANALYSIS RESULTS FOR $1500 \mathrm{KW}$ TURBINE, SANLI UFRA

\begin{tabular}{|c|c|c|c|c|}
\hline \multirow{2}{*}{} & \multicolumn{4}{|c|}{ Turbine } \\
\cline { 2 - 5 } & \multicolumn{2}{|c|}{$1500 \mathrm{Kw}$} & \multicolumn{2}{c|}{$2500 \mathrm{Kw}$} \\
\hline Site & NPW & Payback & NPW & Payback \\
\hline Sanli urfa & $\$ 84,490,496$ & 5 & $\$ 59,785,585$ & 7 \\
\hline Mersin & $\$ 24,038,747$ & 9 & $-\$ 2,590,458$ & 13 \\
\hline
\end{tabular}

The results in Table $\mathrm{V}$ shows that the best results would be get if $1500 \mathrm{kw}$ turbines installed in Sanli urfa. On the other hand, it is showed that it is not feasible to build a farm with $2500 \mathrm{kw}$ turbines in Mersin.

\section{CONCLUSION}

In this study, a wind turbine simulation model integrated with the economic analysis is developed. The characteristics of the wind turbine and wind are accepted as inputs and operational constraints of a wind turbine are included. The model simulates wind turbine over its project life and returns an expected economic value. The analysis can be used by the power producers to have an idea about their future of investments for a given candidate location. The model can further be developed by including real cost data and future power prices as well as a sophisticated wind forecasting method. The availability of the wind turbines, the replacement decisions and new technology challanges can also be included to make the research more attractive. There are developments and researches on the new turbines that increase the efficiency of the operation. These developments can be included to the model to make model more realistic. Also the intermittent nature of the wind is a popular problem of science and it is useful to include it to the model as it is not possible to get a linear power output from the turbine all the time. It affects the amount of real power that is gained from the tubine.

\section{REFERENCES}

[1] S. Krohn et al., "The economics of wind energy," European Wind Energy Association.

[2] Energy information administration. (July 2014). [Online]. Available: http:// www.eia.org

[3] L. Fingersh, M. Hand, A. Laxson, "Wind Turbine Design Cost and Scaling Model", Technical Report NREL/TP- 500-40566, National Renewable Energy Laboratory, Golden, CR, 2006

[4] L. Baringo et al., "Wind power investment: A benders decomposition approach," IEEE Trans. on Power Systems, vol. 27, no. 1, pp. 433-441, 2012.

[5] J. Kazempour et al., "Strategic generation investment using a complementarity approach," IEEE Tran. on Power Systems, vol. 26, no. 2, pp. 940-948, 2011.

[6] R. Gupta et al., "Wind data analysis of Silchar by Rayligh's and Weibull methods," J. of Mech. Engin. Research, vol. 2, no. 1, pp. $10-24,2010$

[7] E. Hau and H. von Renouard, Wind Turbines: Fundamentals, Technologies, Application, Economics, Springer Science, 2013.

[8] A. H. Siddigi et al., "Wind speed simulation using wavelets," American J. of Applied Sciences, vol. 2, no. 2, pp. 557-564, 2005.

[9] TUMAS. Turkish meteorological data center. (July 2014). [Online]. Available: http://tumas.mgm.gov.tr/wps/portal/

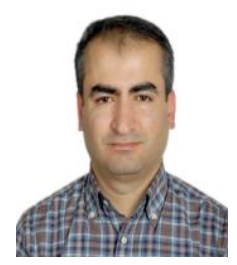

Ahmet Yucekaya is an assistant professor at the Department of Industrial Engineering, Kadir Has University. He holds an undergraduate degree in industrial engineering, a master degree in strategy development from Istanbul Technical University, a master's degree in industrial engineering from University of Pittsburgh and a Ph.D. degree in industrial \& systems engineering from Auburn University. He worked as a research \& teaching assistant at the Department of Industrial Engineering, University of Pittsburgh and Auburn University during his master and doctoral studies. He also has industry experience both in Turkey and USA in application and development of engineering systems for production facilities and energy generation plants. His research interests include energy markets, electric power systems, energy economics, pricing, operations research, logistics and transportation systems, engineering economics analysis, decision support systems, and heuristics algorithms. 

Solar Energy 
